\title{
Canadian Digestive Health Foundation Public Impact Series 3: Irritable bowel syndrome in Canada. Incidence, prevalence, and direct and indirect economic impact
}

\author{
Richard N Fedorak MD FRCPC ${ }^{1}$, Stephen J Vanner MD FRCPC ${ }^{2}$, \\ William G Paterson MD FRCPC ${ }^{2}$, Ron J Bridges MD FRCPC ${ }^{3}$
}

\begin{abstract}
RN Fedorak, SJ Vanner, WG Paterson, RJ Bridges. Canadian Digestive Health Foundation Public Impact Series 3: Irritable bowel syndrome in Canada. Incidence, prevalence, and direct and indirect economic impact. Can J Gastroenterol 2012;26(5):252256.
\end{abstract}

The Canadian Digestive Health Foundation initiated a scientific program to assess the incidence, prevalence, mortality and economic impact of digestive disorders across Canada in 2009. The current article presents the updated findings from the study concerning irritable bowel syndrome.

Key Words: Burden of disease; Canada; Chronic disease; Digestive disease; Epidemiology; Irritable bowel syndrome
The Canadian Digestive Health Foundation (CDHF) launched a scientific project to define incidence, prevalence, mortality and economic impact of digestive disorders across Canada. Detailed information was compiled on 19 digestive disorders through systematic reviews, government documents and websites. This information was published as Establishing Digestive Health as a Priority for Canadians, The Canadian Digestive Health Foundation National Digestive Disorders Prevalence and Impact Study Report, and released to the press and government in late 2009 (www.CDHF.ca). The CDHF Public Impact Series presents a full compilation of the available statistics for the impact of digestive disorders in Canada.

Onset of irritable bowel syndrome (IBS), both constipation and diarrhea predominant, can be associated with a previous gastrointestinal infection; however, for the vast majority of patients, this is not the case, and no initiating factor nor measurable structural or biochemical abnormality can ever be identified (1-3). There are, however, emerging data showing that, compared with asymptomatic controls, many IBS patients have altered levels of signalling molecules in the intestinal tissues (eg, proteases and/or serotonin) and/or have altered sensory processing in the brain, but the pathophysiological relevance of these findings has not been demonstrated (4-6). Furthermore, there has been considerable interest recently in the potential role of the host intestinal bacteria (microbiome) in the expression of IBS $(7,8)$. IBS aggregates within families, suggesting that the cause of the disease has a genetic predilection or exposure to a common environmental agent (9). Overlap of symptoms with other gastrointestinal disorders (eg, gastroesophageal reflux disease, dyspepsia and inflammatory bowel diseases), a wide range of symptoms and extensive comorbid conditions (eg, fibromyalgia and chronic fatigue) adds to the complexity of identifying the underlying cause for IBS $(3,10,11)$.

Previous studies have reported that IBS is a prevalent, chronic and costly disease representing a considerable burden to health care systems, individuals and, by extension, their families. Although data are available, this information has not been extrapolated to the Canadian context in an accessible format. Written to inform both medical

\author{
Troisième article de la série de la Fondation \\ canadienne pour la promotion de la santé digestive \\ sur les répercussions sur le public : l'incidence, la \\ prévalence et les conséquences économiques \\ directes et indirectes du syndrome du côlon \\ irritable au Canada
}

En 2009, la Fondation canadienne pour la promotion de la santé digestive a lancé un programme scientifique pour évaluer l'incidence, la prévalence, la mortalité et les conséquences économiques des maladies digestives au Canada. Le présent article expose les observations mises à jour de l'étude sur le syndrome du côlon irritable.

professionals and patients, the present review will increase awareness of IBS through a comprehensive overview of disease incidence and prevalence, and the Canadian implications for our health care and socioeconomic system.

\section{METHODS}

A systematic literature review was conducted to retrieve peerreviewed, English-language scholarly literature using the PubMed, MEDLINE, EMBASE, Scopus and EvaluatePharma ${ }^{\circledR}$ databases. The search terms used were "irritable bowel syndrome," "functional gastrointestinal disorder" and "IBS", with a specific focus on epidemiology and economic studies from developed countries. Additional information was retrieved from government sources, the World Health Organization and not-for-profit organizations.

\section{INCIDENCE}

The Rome I, II and III criteria were designed to help diagnose IBS and other functional gastrointestinal disorders; however, they are subject to broad interpretations within and between each criteria. For example, there is a 1.5 -fold difference in IBS prevalence rates within the same cohort depending on the interpretation of Rome II criteria (12). Meanwhile, there was a fourfold difference in the prevalence of IBS in the same cohort that was evaluated with Rome II and III criteria (13). In light of the diagnostic issues, it has been difficult to accurately capture prevalence and incidence rates of IBS around the world, and it is not surprising that wide ranges have been reported.

In 1994, a Danish study (14) reported incidence rates ranging from $1 \%$ to $36 \%$, with the variability attributed to inconsistent definitions of IBS. In 2004, the IBS incidence rate for France was estimated to be 3.6 per 1000 population (15), while in the United States, it was two per 1000 person-years (16). The American rate is believed to be much higher because many individuals with mild to moderate symptoms do not seek medical attention and remain undiagnosed. To date, there are no Canadian data regarding the incidence of IBS. However, extrapolating the incidence rates from France provides an approximate estimate that 120,000 Canadians are diagnosed with IBS each year.

\footnotetext{
${ }^{1}$ Division of Gastroenterology, University of Alberta, Edmonton, Alberta; ${ }^{2}$ Division of Gastroenterology, Queen's University, Kingston, Ontario;
}

${ }^{3}$ Division of Gastroenterology, University of Calgary, Calgary, Alberta

Correspondence: Dr Richard N Fedorak, 2-14A Zeidler Building, University of Alberta, Edmonton, Alberta T6G 2 X8.

Telephone 780-492-6941, fax 780-492-8121,e-mail richard.fedorak@ualberta.ca

Received for publication August 18, 2011. Accepted August 19, 2011 


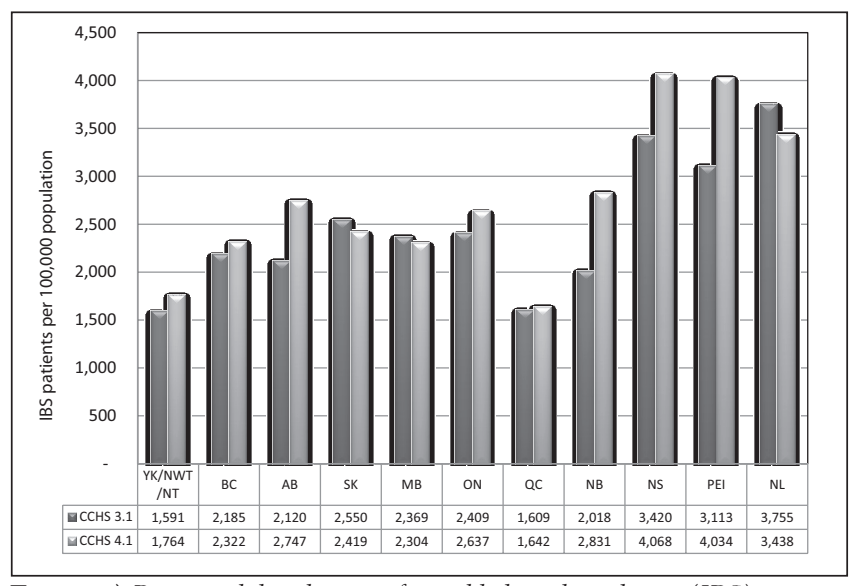

Figure 1) Provincial distribution of irritable bowel syndrome (IBS) patients in 2007/2008. Data adapted from the Canadian Community Health Survey (CCHS), cycle 4.1 (3) and CCHS cycle 3.1 (45). AB Alberta; BC British Columbia; MB Manitoba; NB New Brunswick; NL Newfoundland and Labrador; NS Nova Scotia; NT Nunavut; NWT Northwest Territories; ON Ontario; PEI Prince Edward Island; QC Quebec; SK Saskatchewan; YK Yukon

Postinfectious IBS describes individuals without a history of gastrointestinal complaints who are diagnosed with IBS following an acute enteric infection. A meta-analysis of 18 studies concluded that the pooled incidence rate for this particular form of IBS was 10\% (17). Following an outbreak of acute gastroenteritis due to the contamination of the municipal water of Walkerton, Ontario with Escherichia coli 0157:H7 and Campylobacter jejuni, the odds ratio of developing postinfectious IBS was 4.8 (95\% CI 3.4 to 6.8) (18). The post-infectious IBS incidence rate for Walkerton children $(<16$ years of age) exposed to the contaminated water was $10.5 \%$ compared with $2.5 \%$ for nonexposed children (1).

\section{PREVALENCE}

The Canadian Community Health Survey (CCHS) is a national, population-based survey that collects health and lifestyle information, and is conducted by Statistics Canada. Cycle 4.1 of the CCHS for 2007/2008 specifically collected prevalence information concerning different types of medically diagnosed bowel disorders (19). Extrapolating from this survey, there were approximately 700,000 Canadians selfreporting to Statistics Canada; individuals with IBS represented $2.4 \%$ of the entire population. Earlier results from CCHS cycle 3.1, conducted in 2005, reported a prevalence rate of $2.2 \%$ (20). Previously, a physician-led postal survey study conducted across Canada found the prevalence rate of IBS to be $12.1 \%$ (21). A subsequent physician-led study examining the health-related quality of life of IBS patients concluded that the Canadian prevalence rate was nearly double that (25.2\%) (22). Three other studies examining the prevalence of IBS in the United States and Canada (22-25) reported a mean rate of $15.3 \%$ (9.4\%, $15.0 \%$ and $21.6 \%$, respectively). Using a mid-point value between the range of national prevalence estimates $(6.2 \%$ to $25.2 \%$ [26]), approximately five million Canadians may have IBS. Examining IBS prevalence estimates over the past 30 years highlights the discrepancies between the number of self-reported cases versus medical diagnoses of IBS, as well as the influence of the different medical definitions of IBS such as the Rome and Manning criteria.

Examining the prevalence data according to province, a distinct decrease in prevalence of IBS moving east to west is noted (Figure 1). The sex ratio for IBS patients in Canada is seven females to two males (19), which is similar to that reported for other populations $(27,28)$. This most recent value confirms the sex bias reported in foreign studies, as well as the 1999 Canadian study, which reported a ratio of seven to three for Canadian females to males (29).

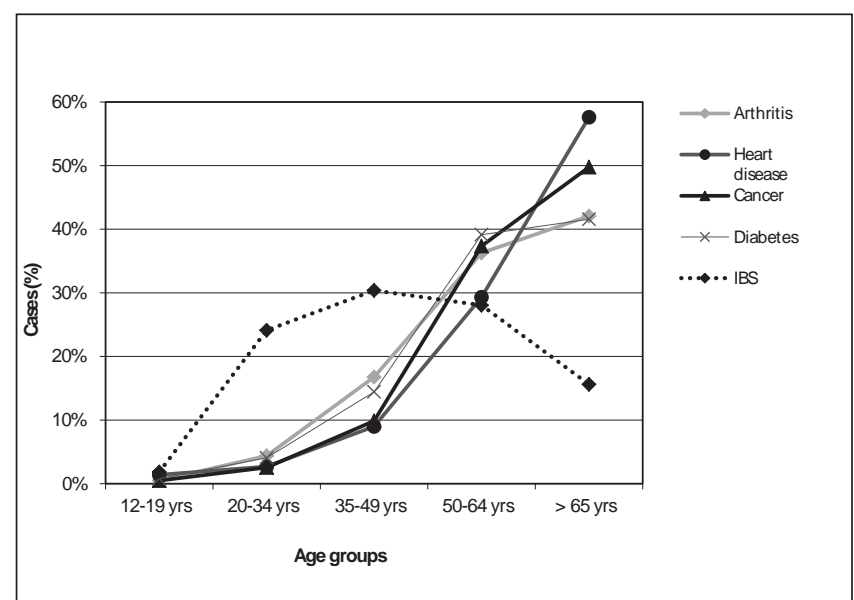

Figure 2) Percentage of individuals with chronic disease categorized according to age group. Data adapted from the Canadian Community Health Survey, cycle 4.1 (3). IBS Irritable bowel syndrome; yrs Years

Because IBS is a chronic condition that remains stable for periods in excess of 10 years in which patients may experience symptom changes (30), the rate differences may be attributed to under-reporting by CCHS participants (31). In support of this interpretation, a cohort of Manitobans was investigated to assess the degree of corroboration between medical records and self-reported survey data concerning IBS. Surprisingly, the investigators found good agreement, except for respondents 65 years of age and older, who dramatically underreported IBS (1.5 cases per 100 population) compared with administrative data (eight cases per 100 population) (31). The real prevalence of IBS in Canada is most likely to be $>6.2 \%$ because many patients fail to seek medical attention for multiple reasons (29). The absence of a reliable estimate for IBS impairs efforts at all levels of health care and government to provide a suitable level of medical care for affected individuals.

In certain population subgroups, the prevalence of IBS is higher than anticipated. For example, $66 \%$ of female chronic hepatitis $\mathrm{C}$ virus patients have IBS, compared with $22 \%$ with chronic hepatitis $B$ virus infection or $18 \%$ in the general population (32). In a study involving American female veterans, a population subgroup who experience a high degree of traumatic events, IBS rates were significantly higher (33). This association suggests that a relationship exists between the psychological effects of trauma and the initiation and perpetuation of IBS.

Childhood IBS prevalence rates have been reported for several regions around the world: $13.9 \%$ (birth to 12 years of age) in Italy, $14 \%$ for boys and $24 \%$ for girls (14 to 17 years of age) in Novosibirsk, Siberia, and $13.25 \%$ (six to 18 years of age) in China (34-36). Closer to home, an American study identified IBS-like symptoms in $17 \%$ and $8 \%$ of students with mean ages of 15.6 years and 12.6 years, respectively (37). Similar to adults, young girls are more likely to have IBS compared with boys of the same age $(34,36)$.

IBS compared with other chronic conditions

Cycle 4.1 of the CCHS specifically addressed the prevalence of $18 \mathrm{com}$ mon, medically diagnosed chronic diseases affecting Canadians, such as back problems, arthritis, asthma, diabetes and emphysema, in addition to IBS (19). In total, there were more than 30 million cases of chronic conditions, with many individuals having multiple issues. The most prevalent chronic condition was back problems, while bowel disorders, including IBS, were ranked 10th, with 1.2 million cases (representing $4 \%$ of all chronic conditions).

Many common chronic conditions, such as arthritis, diabetes and heart disease, manifest in middle age. Conversely, IBS occurs in late adolescence or early adulthood, and persists through to the twilight years. Figure 2 illustrates the percentage of chronic disease cases 


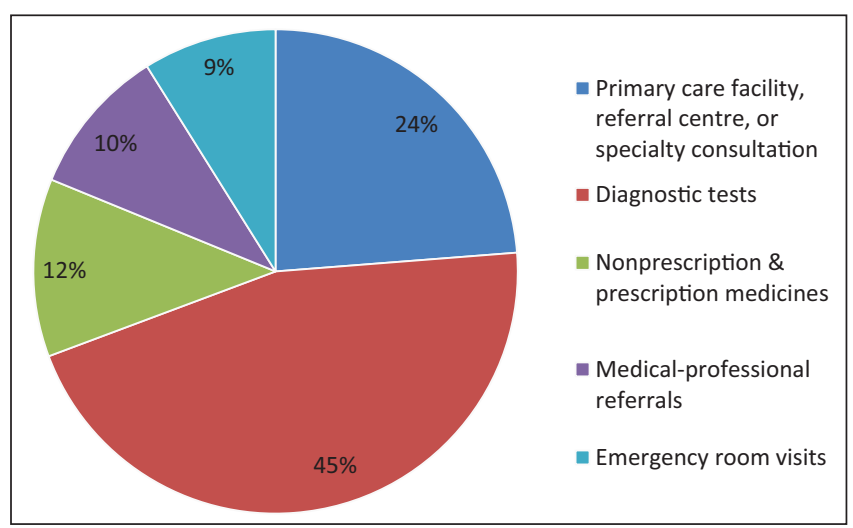

Figure 3) Breakdown of costs for the treatment of irritable bowel syndrome. Data adapted from reference 2

according to age group for 2007/2008, and highlights the early onset of IBS (19). After 65 years of age, the number of IBS patients declines sharply, and this is likely attributed to self-under-reporting.

\section{MORTALITY}

Although a functional disorder, IBS has been implicated as the cause of death in several cases each year. The rationale behind this is that it is not IBS itself that is causing death per se, but more probably an adverse reaction to IBS treatment. The scholarly literature does not directly imply that IBS causes death. Understanding this broad implication of IBS treatment and death, for the years 2000 to 2006, the annual mortality rate reported in death certificates primarily due to IBS was one or two deaths per year, yielding a total of 11 deaths (38). IBS without diarrhea was the primary cause for 10 deaths. The sex ratio for deaths was eight females to three males. Although IBS manifests in youth, the youngest age at the time of death was 45 to 49 years of age, with the majority of deaths occurring in IBS patients 75 years of age or older. In a large, American population-based survey representing 30,000 person-years of follow-up (2), IBS and other functional gastrointestinal disorders did not affect survival rates (HR 1.06 [95\% CI 0.86 to 1.32]). However, individuals affected with chronic constipation were at increased risk of poorer survival, even after adjusting for comorbidities (HR 1.19 [95\% CI 1.03 to 1.37$]$ ). These findings are reflective of the Canadian mortality data concerning IBS.

\section{ECONOMICS}

Variation in IBS symptoms, symptom intensities and a patient's response to therapy make it difficult to accurately capture the total cost of the disease because patients may not seek medical attention, fully adhere to therapies or continue treatments $(26,29)$. Due to the chronicity of symptoms, young age of onset and the negative impact of IBS on individual productivity, IBS was ranked as one of the top 10 most expensive gastrointestinal diseases in the United States (39). In 1995 , the annual direct costs for IBS were estimated to be $\$ 41$ billion, which ranked in the top eight of developed countries (40).

\section{Direct costs}

Direct costs include prescription medications, hospitalizations, surgeries, emergency and physician clinic visits, laboratory and endoscopic investigations, as well as services of allied health care personnel (eg, dieticians, social workers). Although some of these costs can be more easily ascertained than others, based on 18 studies published between 1991 and 2003, the annual direct costs of IBS were estimated to range from US $\$ 348$ to US $\$ 8,750$ per patient (41). Figure 3 illustrates a breakdown of direct costs associated with health care resource use according to IBS patients in Canada.

\section{Pharmaceuticals}

Generally, pharmacological therapy for IBS has proven to be elusive, possibly due to the variation in the pathophysiology of the disease. The

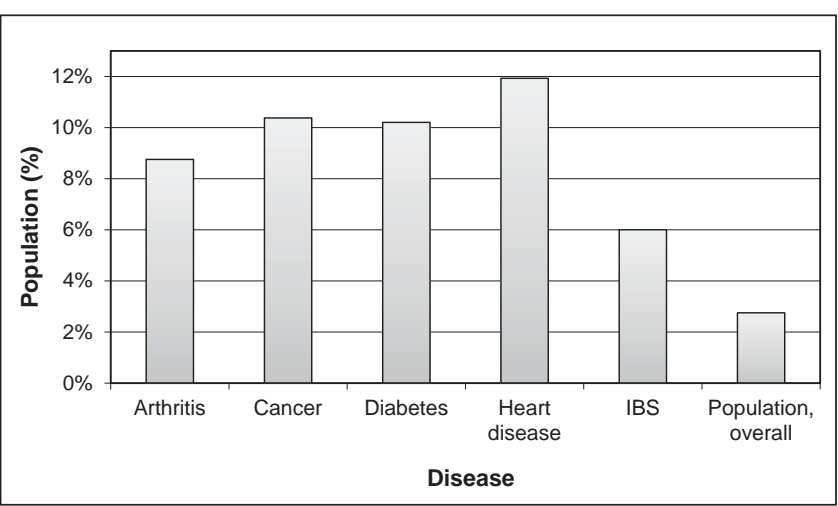

Figure 4) Canadians permanently unable to work categorized according to chronic disease. Data obtained from the Canadian Community Health Survey, cycle 4.1 (3). IBS Irritable bowel syndrome

mainstay of therapy has been involving IBS patients in supportive therapeutic alliance and promoting healthy living (eg, lifestyle and dietary changes, physical exercise) $(3,42,43)$. Presently, drug therapy for IBS is primarily directed at controlling specific symptoms of the syndrome. For patients with diarrhea or constipation, short-term prescriptions of overthe-counter products are suggested depending on symptom severity. In 2008, Canadians spent $\$ 50$ million on diarrheal remedies and $\$ 93.5$ million for laxatives, both of which were over-the-counter products (44). Some IBS patients can benefit from low-dose tricyclic antidepressant medications because these agents attenuate visceral pain (3).

Of particular interest is the high placebo response rate in IBS patients entered in randomized controlled trials (RCTs). A meta-analysis of 73 RCTs (45) found that the pooled placebo response rate was $37.5 \%$ while the rate for individual RCTs ranged from $0 \%$ to $91.7 \%$. Although a small percentage of symptomatic control patients receiving placebo are expected to experience improvements, it is difficult to assess the clinical efficacy of a study drug when as many as one- to two-thirds of the control population improve.

\section{Physician services}

In an American study (46), IBS patients consumed 50\% more health care resources than those who did not have IBS. However, only a minority of IBS patients access health care services specifically for IBS. In 1999, as few as 29\% of Canadian IBS patients actively sought medical attention for their symptoms (26,29). In a 2003 study, it was found that as many as $40 \%$ of Canadian IBS patients had consulted their physician in response to IBS symptoms (22). Before 1995, 25\% to $60 \%$ of IBS patients sought medical attention (40). In comparison, a 2003 study found that as few as $10 \%$ to $29 \%$ of American IBS patients accessed physician services specifically for IBS (39). In 1997, IBS patients accounted for $20 \%$ to $50 \%$ of the referrals to gastroenterologists (47).

\section{Hospitalization}

Compared with the general population, IBS patients have 1.75 -fold higher rates of abdominopelvic and gallbladder surgery than the general population (48). Although the association between IBS and surgery is unclear, the costs should be considered when estimating the overall costs of IBS. IBS alone is not life threatening, and hospitalization is mainly required for patients with comorbidities. Using the Patient Cost Estimator, patients admitted for "other gastrointestinal disorders", which includes IBS, incurred an average cost of $\$ 4,563$, with the average length of hospital stay being four days (49).

\section{Indirect costs}

Employment: As shown in Figure 4, it is evident that the impact of IBS on work productivity is twofold greater than in the general population, although it is lower than for other chronic diseases such as arthritis and heart disease (19). For those who are employed, IBS patients have three 
times more sick days than their non-IBS colleagues (29). In 1993, an American study found that IBS patients missed an average of 13.4 work days per year specifically due to IBS symptoms (23). Using the average weekly earnings from November 2010, the annual cost to an employer is approximately CAD $\$ 2,200$ per IBS patient (50).

\section{Impact of comorbidities}

A recent Norwegian study (51) found that the cost differential between IBS and non-IBS patients was primarily due to treatment for comorbidities, mainly somatic disease and anxieties. During the six-month study, comorbidity-related costs were higher than IBS-related costs for physician services (7.8-fold), hospitalizations (14.5-fold) and medications (63.8-fold). For example, only $19 \%$ of the physician visits for 143 patients (mean 3.4 visits per patient) were due to IBS complaints. Similarly, medication use and the number of missed days from work were greatest for comorbidities other than IBS.

Within the Canadian IBS patient population, it has been reported that as many as $34.4 \%$ may have anxiety disorders, $26.9 \%$ may have abdominal and pelvic symptoms and $10.6 \%$ may have diverticulitis (31). Further study is warranted to determine whether the costs for the treatment of IBS-only symptoms are marginal in comparison with comorbidities.

\section{REFERENCES}

1. Thabane M, Simunovic M, khtar-Danesh N, et al. An outbreak of acute bacterial gastroenteritis is associated with an increased incidence of irritable bowel syndrome in children.

Am J Gastroenterol 2010;105:933-9.

2. Chang JY, Locke GR, III, McNally MA, et al. Impact of functional gastrointestinal disorders on survival in the community. Am J Gastroenterol 2010;105:822-32.

3. Grundmann O, Yoon SL. Irritable bowel syndrome: Epidemiology, diagnosis and treatment: An update for health-care practitioners. J Gastroenterol Hepatol 2010;25:691-9.

4. Malinen E, Krogius-Kurikka L, Lyra A, et al. Association of symptoms with gastrointestinal microbiota in irritable bowel syndrome. World J Gastroenterol 2010;16:4532-40.

5. O'Mahony SM, Bulmer DC, Coelho AM, et al. 5-HT(2B) receptors modulate visceral hypersensitivity in a stress-sensitive animal model of brain-gut axis dysfunction. Neurogastroenterol Motil 2010;22:573-8, e124.

6. Zhou Q, Souba WW, Croce CM, et al. MicroRNA-29a regulates intestinal membrane permeability in patients with irritable bowel syndrome. Gut 2010;59:775-84.

7. Salonen A, de Vos WM, Palva A. Gastrointestinal microbiota in irritable bowel syndrome: Present state and perspectives. Microbiology 2010;156:3205-15.

8. Elsenbruch S. Abdominal pain in irritable bowel syndrome: A review of putative psychological, neural and neuro-immune mechanisms. Brain Behav Immun 2011;25:386-94.

9. Saito YA, Petersen GM, Larson JJ, et al. Familial aggregation of irritable bowel syndrome: A family case-control study. Am J Gastroenterol 2010;105:833-41.

10. Sperber AD, Dekel R. Irritable bowel syndrome and co-morbid gastrointestinal and extra-gastrointestinal functional syndromes. J Neurogastroenterol Motil 2010;16:113-9.

11. Keohane J, O'Mahony C, O'Mahony L, et al. Irritable bowel syndrome-type symptoms in patients with inflammatory bowel disease: A real association or reflection of occult inflammation? Am J Gastroenterol 2010;105:1788-94.

12. Sperber AD, Shvartzman P, Friger M, et al. Unexpectedly low prevalence rates of IBS among adult Israeli Jews. Neurogastroenterol Motil 2005;17:207-11.

13. Sperber AD, Shvartzman P, Friger M, et al. A comparative reappraisal of the Rome II and Rome III diagnostic criteria: Are we getting closer to the 'true' prevalence of irritable bowel syndrome? Eur J Gastroenterol Hepatol 2007;19:441-7.

14. Kay L, Jorgensen T, Jensen KH. The epidemiology of irritable bowel syndrome in a random population: Prevalence, incidence, natural history and risk factors. J Intern Med 1994;236:23-30.

15. Brun-Strang C, Dapoigny M, Lafuma A, et al. Irritable bowel syndrome in France: Quality of life, medical management, and costs: The Encoli study. Eur J Gastroenterol Hepatol 2007;19:1097-103.
16. Locke GR, III, Yawn BP, Wollan PC, et al. Incidence of a clinical diagnosis of the irritable bowel syndrome in a United States population. Aliment Pharmacol Ther 2004;19:1025-31.

17. Thabane M, Kottachchi DT, Marshall JK. Systematic review and meta-analysis: The incidence and prognosis of post-infectious irritable bowel syndrome. Aliment Pharmacol Ther 2007;26:535-44.

18. Marshall JK, Thabane M, Garg AX, et al. Incidence and epidemiology of irritable bowel syndrome after a large waterborne outbreak of bacterial dysentery. Gastroenterology 2006;131:445-50.

19. Statistics Canada - Health Statistics Division. Canadian Community Health Survey (CCHS) Cycle 4.1 2007-2008. Ottawa: Statistics Canada, 2009.

20. Statistics Canada - Health Statistics Division. Canadian Community Health Survey (CCHS) Cycle 3.12005. Ottawa: Statistics Canada, 2006.

21. Thompson WG, Irvine EJ, Pare P, et al. Functional gastrointestinal disorders in Canada: First population-based survey using Rome II criteria with suggestions for improving the questionnaire. Dig Dis Sci 2002;47:225-35.

22. Li FX, Patten SB, Hilsden RJ, et al. Irritable bowel syndrome and health-related quality of life: A population-based study in Calgary, Alberta. Can J Gastroenterol 2003;17:259-63.

23. Drossman DA, Li Z, Andruzzi RD, et al. U.S. householder survey of functional gastrointestinal disorders. Prevalence, sociodemography, and health impact. Dig Dis Sci 1993;38:1569-80.

24. Jones R, Lydeard S. Irritable bowel syndrome in the general population. BMJ 1992;304:87-90.

25. Sandler RS, Drossman DA, Nathan HP, et al. Symptom complaints and health care seeking behavior in subjects with bowel dysfunction. Gastroenterology 1984;87:314-8.

26. Bentkover JD, Field C, Greene EM, et al. The economic burden of irritable bowel syndrome in Canada. Can J Gastroenterol 1999;13:89A-96A.

27. Herman J, Pokkunuri V, Braham L, et al. Gender distribution in irritable bowel syndrome is proportional to the severity of constipation relative to diarrhea. Gend Med 2010;7:240-6.

28. Saito YA, Petersen GM, Larson JJ, et al. Familial aggregation of irritable bowel syndrome: A family case-control study. Am J Gastroenterol 2010;105:833-41.

29. Boivin M. Socioeconomic impact of irritable bowel syndrome in Canada. Can J Gastroenterol 2001;15:8B-11B.

30. Olafsdottir LB, Gudjonsson H, Jonsdottir HH, et al. Stability of the irritable bowel syndrome and subgroups as measured by three diagnostic criteria - a 10-year follow-up study. Aliment Pharmacol Ther 2010;32:670-80.

31. Lix LM, Yogendran MS, Shaw SY, et al. Comparing administrative and survey data for ascertaining cases of irritable bowel syndrome: A population-based investigation. BMC Health Serv Res 2010;10:31.

32. Fouad YM, Makhlouf MM, Khalaf $\mathrm{H}$, et al. Is irritable bowel syndrome associated with chronic hepatitis C? J Gastroenterol Hepatol 2010;25:1285-8.

33. White DL, Savas LS, Daci K, et al. Trauma history and risk of the irritable bowel syndrome in women veterans. Aliment Pharmacol Ther 2010;32:551-61.

34. Dong L, Dingguo L, Xiaoxing X, et al. An epidemiologic study of irritable bowel syndrome in adolescents and children in China: A school-based study. Pediatrics 2005;116:e393-e396.

35. Miele E, Simeone D, Marino A, et al. Functional gastrointestinal disorders in children: An Italian prospective survey. Pediatrics 2004;114:73-8.

36. Reshetnikov OV, Kurilovich SA, Denisova DV, et al. Prevalence of dyspepsia and irritable bowel syndrome among adolescents of Novosibirsk, western Siberia. Int J Circumpolar Health 2001;60:253-7.

37. Hyams JS, Burke G, Davis PM, et al. Abdominal pain and irritable bowel syndrome in adolescents: A community-based study. J Pediatr 1996;129:220-6.

38. Statistics Canada. CANSIM - Table 102-0531 - Deaths, by cause, Chapter XI: Diseases of the digestive system (K00 to K93), age group and sex, Canada, annual (2000-2006). <http://cansim2. statcan.gc.ca> (Accessed July 28, 2010).

39. Inadomi JM, Fennerty MB, Bjorkman D. Systematic review: The economic impact of irritable bowel syndrome. Aliment Pharmacol Ther 2003;18:671-82.

40. Talley NJ, Zinsmeister AR, Melton LJ, III. Irritable bowel syndrome in a community: Symptom subgroups, risk factors, and health care utilization. Am J Epidemiol 1995;142:76-83. 
41. Maxion-Bergemann S, Thielecke F, Abel F, et al. Costs of irritable bowel syndrome in the UK and US. Pharmacoeconomics 2006;24:21-37.

42. Paterson WG, Thompson WG, Vanner SJ, et al. Recommendations for the management of irritable bowel syndrome in family practice. CMAJ 1999;161:154-60.

43. Johannesson E, Simren M, Strid H, et al. Physical activity improves symptoms in irritable bowel syndrome: A randomized controlled trial. Am J Gastroenterol 2011;106:915-22.

44. Organisation for Economic Co-operation and Development (OECD). OECD Health Data 2009. <www.oecd.org> (Accessed January 2, 2011).

45. Ford A, Moayyedi, P. Meta-analysis: Factors affecting placebo response rate in the irritable bowel syndrome. Aliment Pharmacol Ther 2010;32:144-58.
46. Spiegel BM, Kanwal F, Naliboff B, et al. The impact of somatization on the use of gastrointestinal health-care resources in patients with irritable bowel syndrome. Am J Gastroenterol 2005;100:2262-73.

47. Maxwell PR, Mendall MA, Kumar D. Irritable bowel syndrome. Lancet 1997;350:1691-5.

48. Cole JA, Yeaw JM, Cutone JA, et al. The incidence of abdominal and pelvic surgery among patients with irritable bowel syndrome. Dig Dis Sci 2005;50:2268-75.

49. Canadian Institute for Health Information. Patient Cost Estimator 2008-2009. <www.cihi.ca> (Accessed January 2, 2011).

50. Statistics Canada. Economic Indicators, Table 281-0039. $<$ www.statcan.gc.ca> (Accessed February 1, 2011).

51. Johansson PA, Farup PG, Bracco A, et al. How does comorbidity affect cost of health care in patients with irritable bowel syndrome? A cohort study in general practice. BMC Gastroenterol 2010;10:31. 


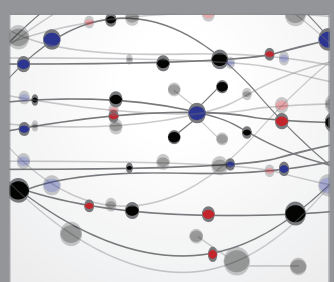

The Scientific World Journal
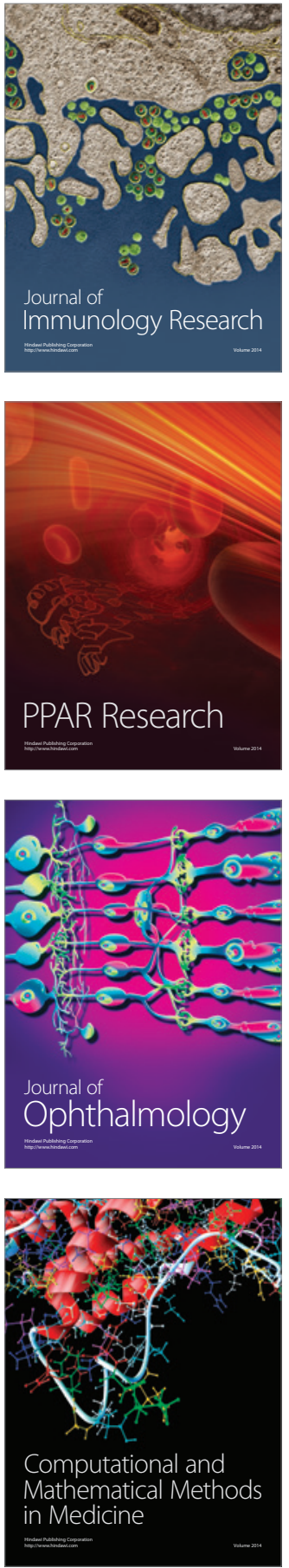

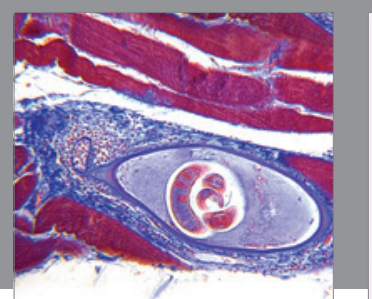

Gastroenterology Research and Practice

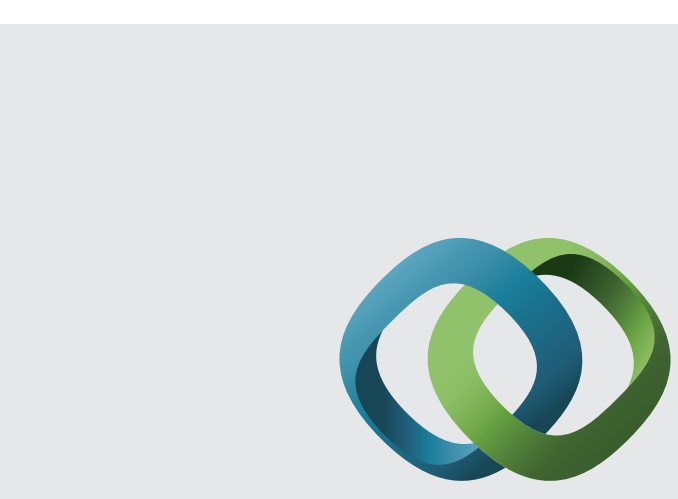

\section{Hindawi}

Submit your manuscripts at

http://www.hindawi.com
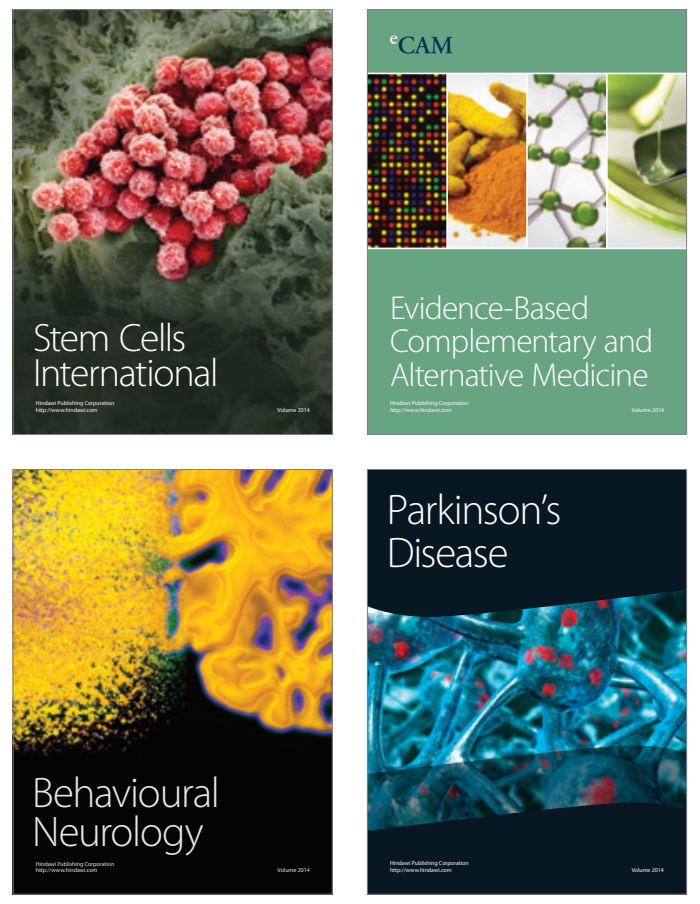
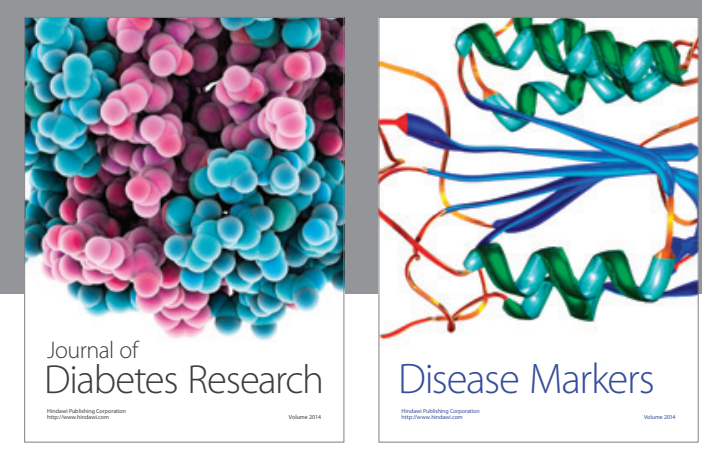

Disease Markers
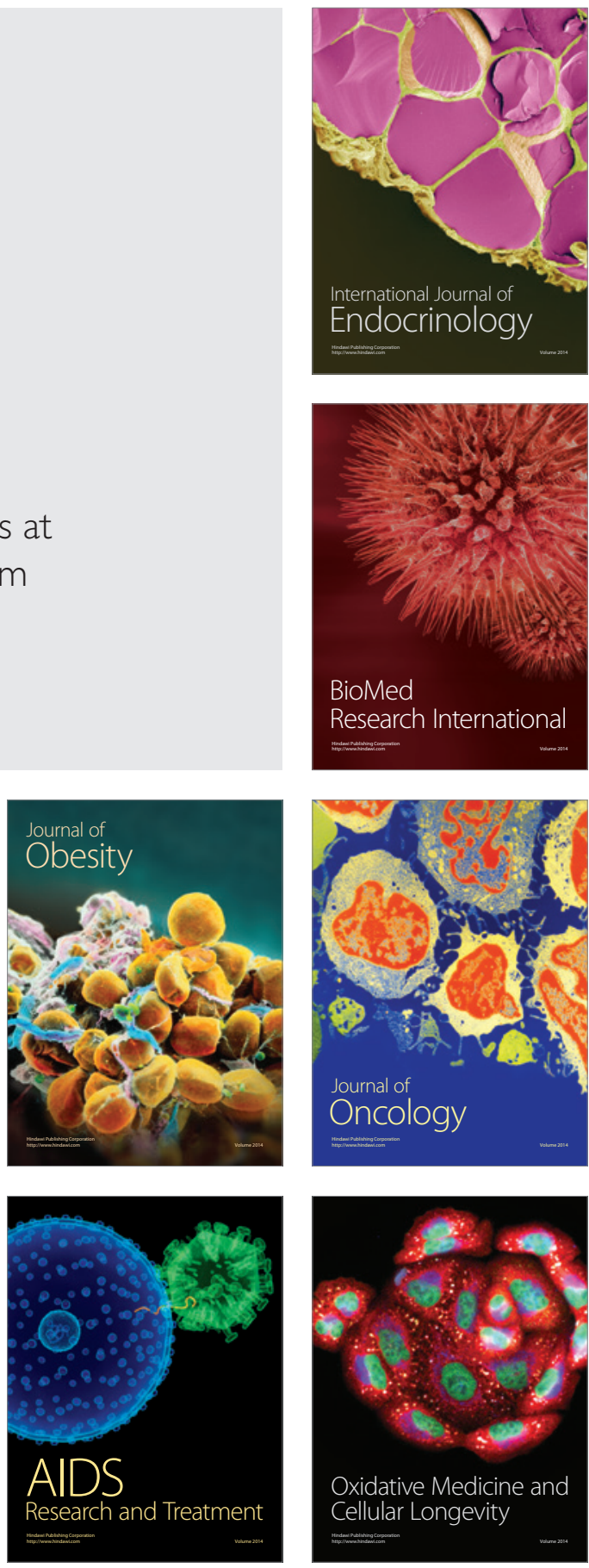